\title{
Building entrepreneurial ecosystems: the case of Coimbra
}

\author{
Domingos_Santos \\ Journal of Science and Technology Policy Management
}

ISSN: 2053-4620

Article publication date: 1 March 2021 \&eprints \& Permissions

Issue publication date: 2 February 2022

DOWNLOADS

109

\section{Abstract}

\section{Purpose}

The purpose of this paper is three-fold. The first objective is to contextualize and clarify the concepts of regional innovation systems and entrepreneurship, addressing their differences and complementarities and suggesting an analytical filter to enhance their understanding. The second aim is to question and analyse the challenges this renewed approach brings to the domain of territorial policy, namely, the role it may bring to local and regional development strategies, opening up the way for a set of public policy interventions on the fields of entrepreneurship and innovation promotion. Finally, the paper presents and analyses the example of Coimbra, a mediumsized city in Portugal, underlining both the role of academia and the Instituto Pedro Nunes-Incubator have had on these domains.

\section{Design/methodology/approach}

The paper is based on a case study approach, with an in-depth descriptive and exploratory analysis of the Coimbra entrepreneurial ecosystem.

\section{Findings}

The paper acknowledged the role entrepreneurial stakeholders have on the fertilization of the innovation and entrepreneurial Coimbra ecosystem. The Instituto Pedro Nunes-Incubator, with a new generation of startups, mostly born on its infrastructure as university spin-offs, gradually introduced a more business-oriented perspective on the local innovation system which, alongside the creation of a thicker networking and more profound cooperation culture, with the growing involvement of other local stakeholders such as science parks 
(Coimbra iParque), has had a decisive role on upgrading urban competitiveness. These new knowledge-based startups also have important spill-over effects that are beneficial to the growth of other firms in the same locality. There is evidence that they also provide an important Schumpeterian stimulus within economies by increasing competition, promoting innovation and augmenting the efficient allocation of resources within economies. Besides the more traditional transactional forms of support (tax incentives, grants, etc.), there is now the recognition that relational forms of support such as network building, developing connections between entrepreneurial actors, institutional alignment of priorities, fostering peer-based interactions have been strategic to improve both the efficiency and the effectiveness of the entrepreneurial ecosystem.

\section{Research limitations/implications}

There is, thus, a need for more profound theorization and empirical research that can produce additional comprehension into this domain of the causeeffect relationships between entrepreneurship, innovation and local and regional dynamics. Some authors suggest, in particular, that the existing work on entrepreneurial ecosystems within popular business literature and academic research still has a deficit of a solid theoretical foundation, making the entrepreneurial ecosystem approach somehow both ambiguous and immature concept and, thus, reducing its generalizability and policy applicability. Research that evaluates the relationship between entrepreneurial performance and the level of government participation as part of governance systems will also be of great significance over the near future as it will help researchers and policymakers to realize better where the different stakeholders can enhance entrepreneurship and where their intervention will possibly diminish positive outcomes.

\section{Practical implications}

The main practical implications of this paper are associated with the need that urban and regional policymakers to formulate more business-led strategies to promote territorial innovation and entrepreneurship. The paper also offers conceptual tools that point out the need that innovation stakeholders, namely, universities, incubators and firms, have to assume more protagonism in promoting competitiveness and sustainability.

\section{Social implications}

The entrepreneurial ecosystem approach constitutes both a theoretical and analytical useful tool to define competitive strategies for urban and regional economies. Urban and regional-innovation ecosystem construction is a representative method of realizing territorial development and competition enhancement, through sustainable job and wealth creation. 


\section{Originality/value}

This paper analysis summarizes and integrates the increasing and scattered literature of both the regional innovation systems and of the entrepreneurial ecosystems and delivers new insights for the future development of this field, namely, in terms of renewal of policy formulation and implementation. The singularity of the case study is associated with the fact that Coimbra entrepreneurial ecosystem is still largely embryonic, having its roots on a paradigm strategic shift the University adopted towards a more proactive role in terms of city aand regional development.

\section{Keywords}

Regional innovation systems; Innovation policy; Entrepreneurial ecosystems; Coimbra; Instituto Pedro Nunes

\section{Citation}

Santos, D. (2022), "Building entrepreneurial ecosystems: the case of Coimbra", Journal of Science and Technology Policy Management, Vol. 13 No. 1, pp. 73-89. https://doi.org/10.1108/JSTPM-02-2020-0028

Download as .RIS

\section{Publisher}

Emerald Publishing Limited

Copyright $\odot$ 2021, Emerald Publishing Limited 